\title{
Performance of Prototype Pneumatic Boxing Gloves under Two Different Conditions of Target Padding
}

\author{
Paul Perkins 1,2, Alex Jamieson'1, Wayne Spratford1, Allan Hahn',3,4 \\ ${ }^{1}$ University of Canberra, Australian Capital Territory, Australia \\ ${ }^{2}$ Boxing Australia Limited, Canberra, Australia \\ ${ }^{3}$ Queensland Academy of Sport, Brisbane, Australia \\ ${ }^{4}$ Griffith University, Brisbane, Australia \\ Email: paul.perkins@boxing.org.au
}

How to cite this paper: Perkins, P., Jamieson, A., Spratford, W. and Hahn, A. (2018) Performance of Prototype Pneumatic Boxing Gloves under Two Different Conditions of Target Padding. World Journal of Engineering and Technology, 6, 603-624. https://doi.org/10.4236/wjet.2018.63037

Received: June 28, 2018

Accepted: July 27, 2018

Published: July 30, 2018

Copyright $\odot 2018$ by authors and Scientific Research Publishing Inc. This work is licensed under the Creative Commons Attribution International License (CC BY 4.0).

http://creativecommons.org/licenses/by/4.0/

\begin{abstract}
The impact damping capabilities of four different boxing gloves were assessed under two different conditions of target padding to determine whether target characteristics might influence previous conclusions concerning potential for impact mitigation through novel glove design. A conventional 10 oz glove (Std $10 \mathrm{oz}$ ), a conventional $16 \mathrm{oz}$ glove (Std $16 \mathrm{oz}$ ), a prototype pneumatic glove with a sealed bladder (SBLI) and a prototype pneumatic glove with a bladder allowing air exchange with the external environment (ARLI) were each dropped three times on to a force plate from six heights ranging from 2.5 to 5.0 metres. The force plate was covered by a $50 \mathrm{~mm}$ thick mat of EVA material and results obtained were compared with those of an earlier experiment involving use of a similar protocol but a $25 \mathrm{~mm}$ thick EVA force plate covering. The thicker mat greatly reduced peak impact forces for all gloves, with values for the Std $10 \mathrm{oz}$ glove becoming much closer to those reported by other researchers for punches delivered by elite boxers to crash test manikins. Peak rates of force development were also substantially decreased. Protective effects provided by the ARLI glove relative to the Std 10 oz glove were diminished but still in the order of $17 \%-22 \%$ for peak impact force and $27 \%-49 \%$ for peak rate of force development across the range of drop heights. With the $50 \mathrm{~mm}$ mat thickness, the SBLI glove was as effective as the ARLI glove in reducing peak impact force, whereas this was not the case with the $25 \mathrm{~mm}$ mat. It was, however, always inferior to the ARLI glove in decreasing peak rate of force development. The ability of the ARLI glove to afford protection across a spectrum of impact conditions could yield important practical advantages.
\end{abstract}




\section{Keywords}

Boxing Safety, Low-Impact Boxing Gloves, Modified Boxing, Protective Equipment for Boxing, Sport Technology, Sport Safety

\section{Introduction}

A paper recently published by our group showed that a pneumatic boxing glove allowing transfer of air between the glove bladder and the external environment substantially reduced peak impact forces and rates of force development (i.e. loading rates) across the whole range of impact magnitudes likely to occur in boxing [1]. We described a study in which prototype pneumatic gloves containing a mechanical fist with a mass of $\sim 3 \mathrm{~kg}$ were dropped on to a force plate from heights of up to 5 metres to simulate the effective impact mass and pre-impact glove velocities previously reported by Waliliko et al. [2] for a group of elite boxers.

Even though the force plate was covered by a $25 \mathrm{~mm}$ thickness of ethylene-vinyl acetate (EVA) material known to have high capacity for shock absorption, we recorded peak impact forces of more than 13,000 Newtons (N) when conventional $10 \mathrm{oz}$ and $16 \mathrm{oz}$ gloves were dropped from a height of 5 metres. There have been some studies in which boxers have delivered maximal punches to the heads of Hybrid III crash test manikins designed to closely simulate human structural characteristics [2] [3]. In this situation, mean peak impact forces have been less than $4000 \mathrm{~N}$ although several boxers have generated readings of more than $5000 \mathrm{~N}$. The highest value recorded in the scientific literature is $8000 \mathrm{~N}$ [3]. Pierce et al. [4] used in-glove capacitive force sensors to record peak impact forces during six professional boxing bouts incorporating a total of 20 rounds. Single highest peak force readings for the 12 contestants averaged $3295 \mathrm{~N}$ and the highest reading produced by any boxer was 5358 $\mathrm{N}$.

The above suggests that human anatomical structures typically provide considerably more impact damping than the EVA-covered force plate used in our experiment. This accords with a contention by Margetts [5] that published data on the peak forces produced by a champion heavyweight boxer in a laboratory setting may lack ecological validity because of differences in the characteristics of the experimental and real-world targets.

We thought it logical that an impact-damping boxing glove that was effective in reducing the peak forces of impacts to a relatively undamped target might be much less so when additional impact buffering mechanisms are brought into play. It also seemed possible that testing of gloves in the latter situation might influence the relativity of the protective effects offered by the air-release pneumatic glove and a prototype with a sealed bladder. In our initial work, we found that performance of the two gloves was similar at drop heights of $1-2.5$ metres, 
but that at higher drop heights the impact-damping capacity of the sealed-bladder glove progressively "bottomed out". It was evident that in a more damped system such loss of protective ability might not occur, and that a pneumatic glove with a sealed bladder might therefore perform as well as one enabling air exchange.

Accordingly, we decided to test the gloves used in our earlier experiment under conditions in which the force plate was more padded and the peak impact forces therefore would be more akin to those recorded in research involving the use of Hybrid III manikins [2] [3] and measurements made during boxing contests [4].

\section{Methods}

Four different boxing gloves were placed on to a mechanical fist and dropped on to an in-floor Kistler force plate (Kistler, Amherst, MA, USA) three times from each of six heights starting at 2.5 metres and progressing in 0.5 -metre increments to 5.0 metres. The four gloves were a conventional $10 \mathrm{oz}$ (Std $10 \mathrm{oz}$ ) glove of the type used in competition by male amateur boxers weighing up to $64 \mathrm{~kg}$ and by female amateur boxers in all weight divisions [6], a conventional $16 \mathrm{oz}$ glove (Std $16 \mathrm{oz}$ ) of the type often used by boxers in sparring [7], a prototype pneumatic glove with a sealed bladder (SBLI), and a prototype pneumatic glove with a bladder that allowed air release to the external environment and subsequent air reuptake (ARLI).

The Std $10 \mathrm{oz}$ and Std $16 \mathrm{oz}$ gloves were made by Sting Sports (Melbourne, Australia) and were commercially available. Sting Sports was the official supplier of gloves for the 2016 Olympic Games and 2018 Commonwealth Games. The SBLI and ARLI gloves were manufactured by Stellen Studio (Canberra, Australia) for our research purposes. An overview of their construction is available elsewhere [1]. Precise glove masses, as measured with digital kitchen scales, were $278 \mathrm{~g}$ (9.8 oz), $455 \mathrm{~g}(16.0 \mathrm{oz}), 227 \mathrm{~g}(8.0 \mathrm{oz})$ and $298 \mathrm{~g}(10.5 \mathrm{oz})$ for the Std 10 oz, Std 16 oz, SBLI and ARLI gloves respectively.

The mechanical fist, shown in Figure 1, had a mass of $3.046 \mathrm{~kg}$ which is close to the average effective mass of punches delivered by elite boxers [2]. It consisted of three sections simulating the long axis of the forearm, the proximal section of the fingers, and the distal sections of the fingers. These sections were hinged together and a ratchet mechanism enabled them to be drawn and locked into a position resembling a closed fist [1]. In the case of the Std $10 \mathrm{oz}$ and Std $16 \mathrm{oz}$ gloves, the mechanical hand was placed into the glove and the fist was then closed. For the SBLI and ARLI gloves, the fist was closed and then placed into the glove such that the bladder was located between the fist and the target. These approaches accorded with intended placement of human fists into the gloves in the real world.

The force plate had a surface area of $600 \mathrm{~mm} \times 400 \mathrm{~mm}$. This surface was covered by a $50 \mathrm{~mm}$ thickness of EVA75 material (Ultralon Foam Group, Sydney, 

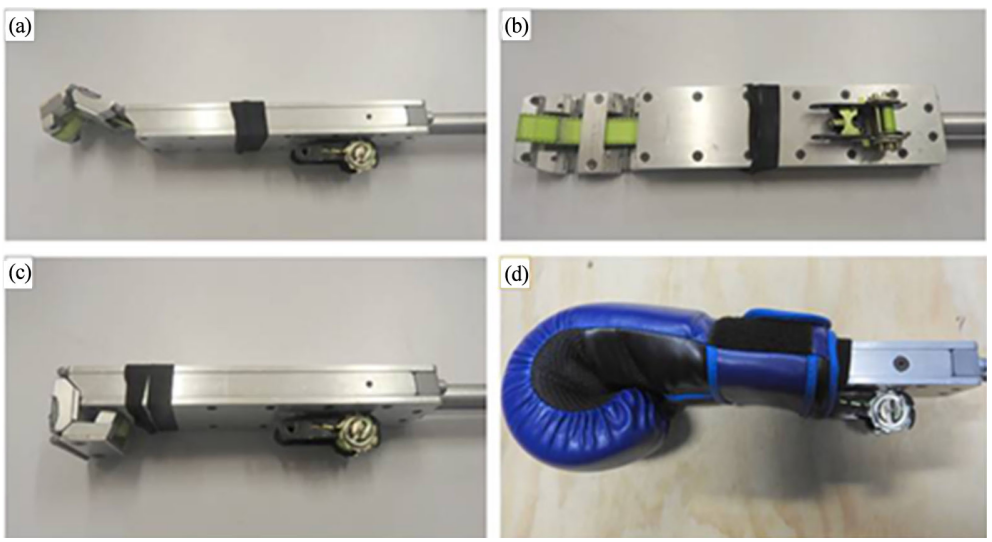

Figure 1. The mechanical fist used in the experiment. Panel (a) shows the three hinged metal sections of the fist; Panel (b) shows the mechanism used to draw the fist closed; Panel (c) shows the fist in the locked position; Panel (d) shows a glove fitted to the fist and highlights the accuracy with which normal glove positioning on a fist was simulated.

Australia) comprising two $25 \mathrm{~mm}$ thick layers joined together by double-sided tape. For each glove drop, the force plate was sampled at 10,000 Hz. Throughout the experiment, known masses were repeatedly placed on the force plate to check its measurement accuracy.

A Vicon Motion Capture System (Oxford Metrics Ltd., Oxford, UK) with four cameras each sampling at 500 frames per second was used to determine glove velocities just before and after impact with the force plate. Markers placed on gloves allowed determination of displacement and thus calculation of velocity over successive 2-msec time periods. To facilitate data synchronization, the Vicon software was used to capture data from the cameras and the force plate. Glove contact with the force plate was defined as the period between occurrence of a force continuously above $20 \mathrm{~N}$ in the ascending phase of the force-time curve and return of the force to readings below $20 \mathrm{~N}$ in the descending phase. Employment of the $20 \mathrm{~N}$ threshold ensured that identification of contact would not be contaminated by previously quantified levels of baseline noise in force plate electrical activity. The drop testing system used in the experiment is shown in Figure 2.

The SBLI glove was tested first, followed by the ARLI, Std $10 \mathrm{oz}$ and Std $16 \mathrm{oz}$ gloves in that order. Each glove was tested at all drops heights before progression to the next glove.

Data obtained with the $50 \mathrm{~mm}$ thickness of EVA75 material covering the force plate were compared to those derived from an earlier experiment [1] in which the thickness of the covering was only $25 \mathrm{~mm}$. The earlier experiment was conducted during the preceding week, meaning that the time between the experiments with the $25 \mathrm{~mm}$ and $50 \mathrm{~mm}$ mats was sufficiently short to allow valid data comparison.

Also, exactly the same gloves (rather than just the same glove types) were used in the two studies. In the research involving deployment of the $25 \mathrm{~mm}$ mat, each glove was dropped on to the force plate 10 times from each height [1], but for the 


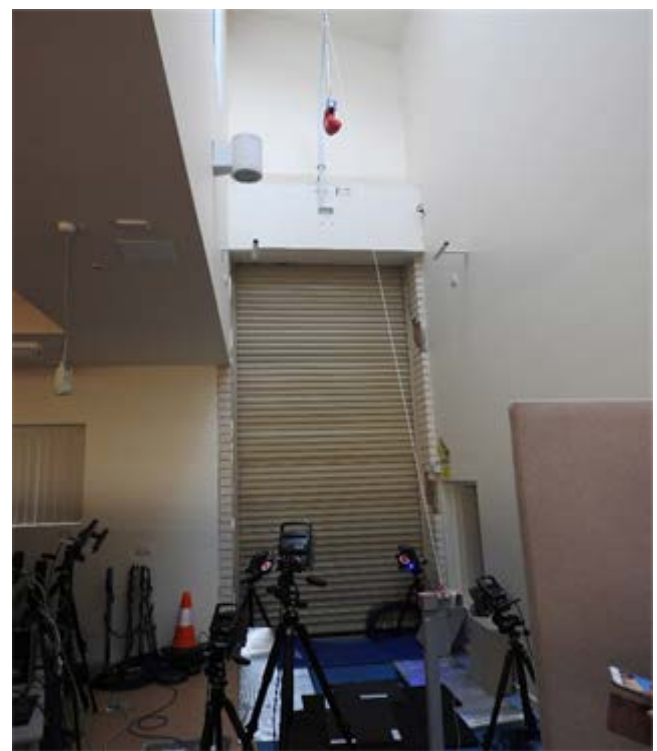

Figure 2. Drop testing system used for the experiment.

present purpose only the data from the first three of these drops were analyzed. This permitted direct alignment with the three drops made from each drop height in the experiment with the $50 \mathrm{~mm}$ mat.

\section{Results}

The peak impact forces recorded with the $50 \mathrm{~mm}$ mat covering the force plate are shown Figure 3.

For all glove types the values were lower than those we obtained in the experiment conducted during the preceding week with a thinner $(25 \mathrm{~mm})$ mat covering the force plate. The peak forces measured when the Std $10 \mathrm{oz}$ glove was dropped from 5 metres were much closer to the maximum levels that others have reported for boxers in laboratory or real-world competitive situations [2] [3] [4]. The two prototype pneumatic gloves reduced peak forces relative to those seen with the Std $10 \mathrm{oz}$ and Std $16 \mathrm{oz}$ gloves, but in contrast to our finding when the thinner force plate covering was used, the SBLI glove was now almost as effective as the ARLI glove across the whole range of impact magnitudes. The values for the Std $16 \mathrm{oz}$ glove were slightly higher than those for the Std $10 \mathrm{oz}$ glove, whereas before they had been slightly lower.

Figure 4 shows how the peak impact forces for specific combinations of glove type and drop height were influenced by the thickness of the force plate covering. The grey-shaded regions of the graphs highlight the magnitude of change in peak force as a function of mat thickness. It can be readily seen that mat thickness had less effect on the ARLI glove than on any of the others. The areas of the grey regions were computed, and the results, which are presented in the figure, provided objective quantification of the visual impression. The calculated areas showed that overall, the Std $10 \mathrm{oz}$ and SBLI gloves were most affected by mat thickness, followed by the Std $16 \mathrm{oz}$ glove and then the ARLI glove. 


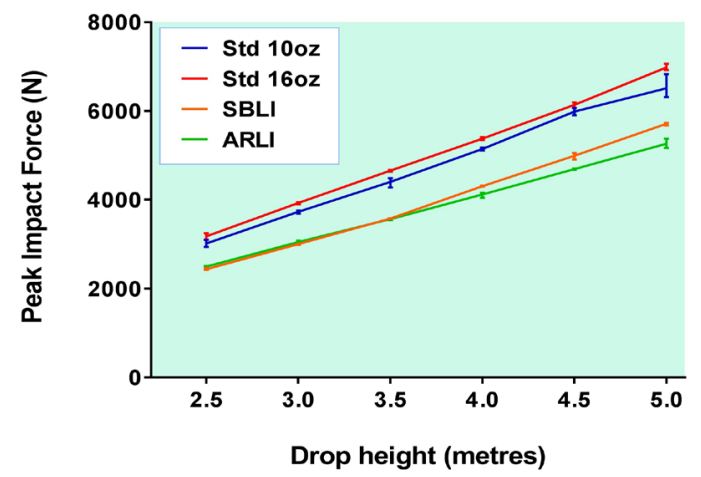

Figure 3. Effect of glove type and drop height on peak impact force when gloves were dropped on to a $50 \mathrm{~mm}$ thick mat consisting of EVA75 material with a guaranteed Shore A hardness rating of 30 35. Each point on the graph shows the mean and the range for three glove drops. In some cases, the range is too small to be perceptible.
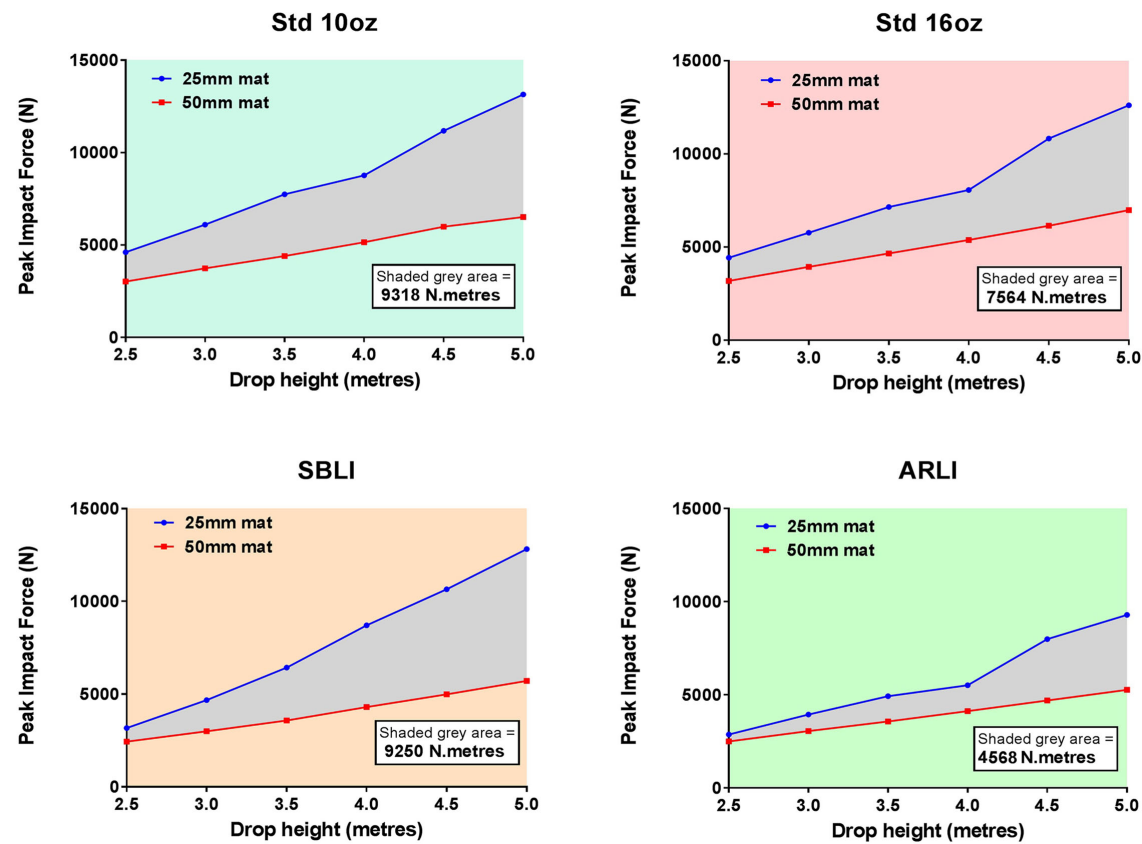

Figure 4. Effect of thickness of force plate covering on peak impact forces associated with dropping different gloves from various heights. Each point on the graphs is a mean value for three glove drops.

For each glove type, both the absolute and proportional magnitude of the reduction in peak force with increase in mat thickness tended to become greater with drop height. Percentage reductions for the various drop heights are shown in Figure 5.

Because the four gloves were differently affected by mat thickness, the relativity of their protective performance was influenced. For example, Figure 6 shows that compared to the Std $10 \mathrm{oz}$ glove, the ARLI glove reduced peak impact force by $29 \%-37 \%$ when the thickness of the mat covering the force plate was $25 \mathrm{~mm}$, but only by $17 \%-22 \%$ when the thickness was $50 \mathrm{~mm}$. With the thinner mat, 
the percentage reduction in peak force provided by the ARLI glove tended to decrease as drop height increased. When the thicker mat was used, it was relatively stable across the range of drop heights. Consequently, for the ARLI glove, the difference in percentage reduction of peak force observed with the two mat thicknesses was least when the drop heights were highest.

For all glove types, the peak pre-impact glove velocities determined by the Vicon Motion Capture System were slightly less with the $50 \mathrm{~mm}$ force plate padding than in our previous experiment where $25 \mathrm{~mm}$ padding was used. This reflected the fact that the additional padding of the force plate decreased the actual drop heights by $2.5 \mathrm{~cm}$. The peak impact velocities were always slightly lower for the two prototype pneumatic gloves than for the two conventional gloves (Figure 7), as was observed also in our immediately preceding research entailing use of $25 \mathrm{~mm}$ padding.

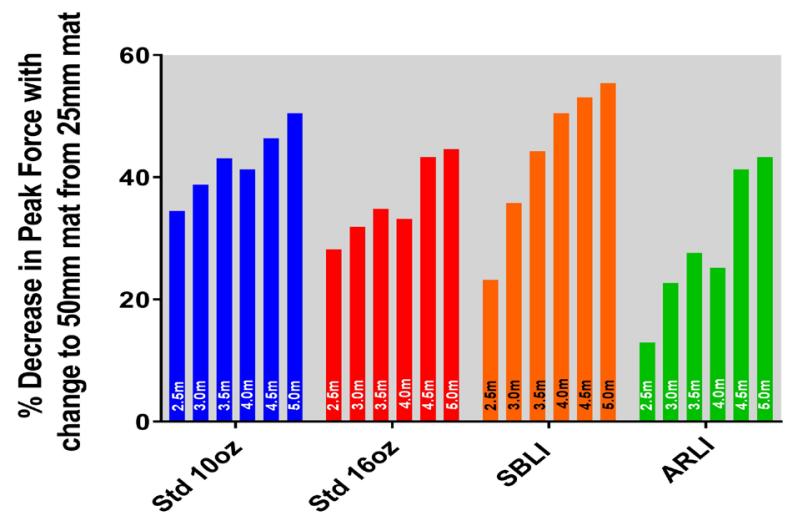

Figure 5. Percentage reduction in peak impact force resulting from covering the force plate with a $50 \mathrm{~mm}$ thickness of EVA75 foam as opposed to a $25 \mathrm{~mm}$ thickness. Each bar represents the decrease calculated from means of three peak force readings obtained with each mat thickness. Drop heights are shown on the bars.

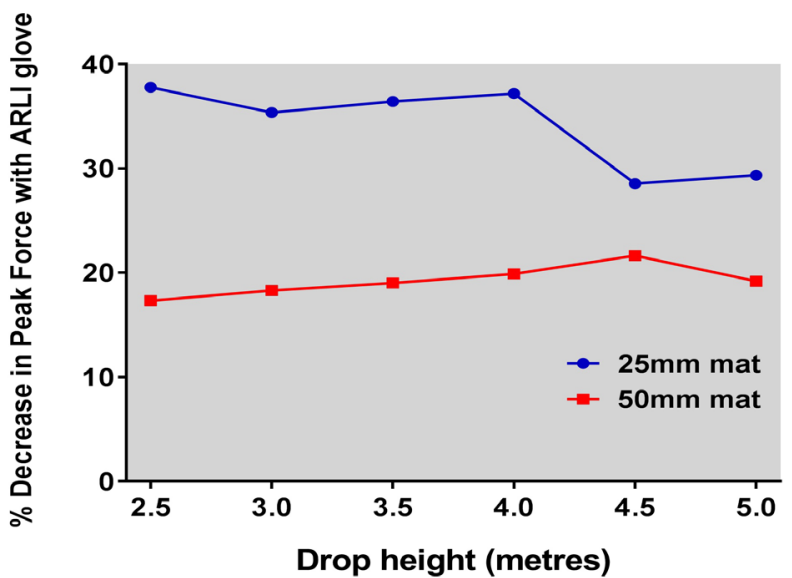

Figure 6. Effect of thickness of force plate covering on percentage reduction in peak force provided by ARLI glove relative to Std $10 \mathrm{oz}$ glove. 


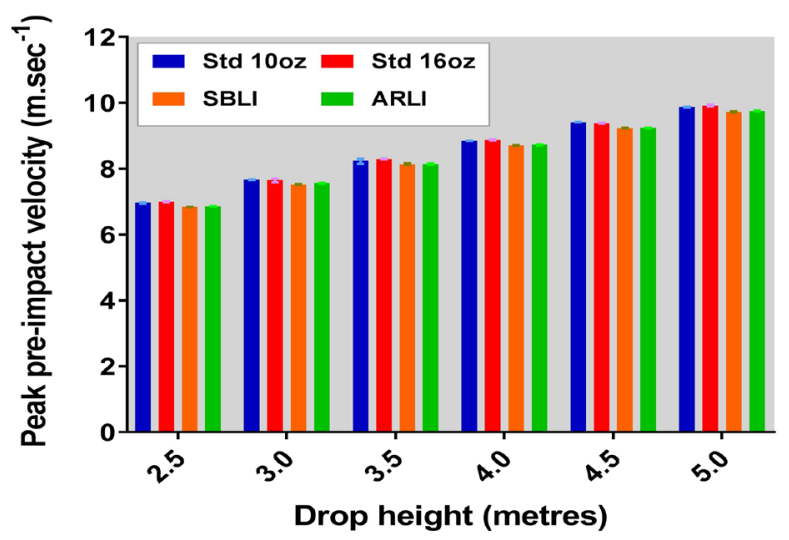

Figure 7. Peak pre-impact glove velocities (in $\mathrm{m} \cdot \mathrm{sec}^{-1}$ ) for four different gloves dropped from various heights on to a force plate covered with a $50 \mathrm{~mm}$ thick mat of EVA75 material. Each bar indicates the mean for three glove drops under the specified condition and the range of the readings is also shown.

The velocity data revealed that at drop heights of 2.5 to 3.5 metres, slowing during the first few video frames after contact was essentially unchanged by extra force plate padding for any of the gloves. At a drop height of 4.0 metres, higher velocities during the immediate post-contact period became evident for the Std 16 oz glove and this was observed also at 4.5 and 5.0 metres. For the Std $10 \mathrm{oz}$ and SBLI gloves, higher velocities were seen only at 4.5 and 5.0 metres. In the case of the ARLI glove, there was no change up to and including 4.5 metres, and only a very slightly higher post-contact velocity even at 5.0 metres. For illustrative purposes, data for the Std $10 \mathrm{oz}$ and ARLI gloves at drop heights of 2.5 and 5.0 metres (the extremes of the range of drop heights employed) are presented in Figure 8. We interpreted the data as indicating that the initial dynamics of the interaction between glove and force plate padding were determined by the properties of the padding material rather than its thickness, and that the added thickness became important in reducing glove deceleration only once the ability of the structural characteristics of the gloves to exert that effect began to approach a maximum.

The above interpretation was supported by analysis of force-time curves recorded from the force plate. For each glove type at every drop height, there was a period of a few milliseconds after contact when force-time curves obtained with the $25 \mathrm{~mm}$ and $50 \mathrm{~mm}$ mats covering the force plate essentially overlaid each other (Figure 9). It seems logical to presume that during this period (which was generally longer for the two prototype pneumatic gloves than for the Std $10 \mathrm{oz}$ and Std $16 \mathrm{oz}$ gloves), the primary influence on the curve was glove compression. With the gloves being softer than the target, it can be easily envisaged that their deformation would be the predominant event in the initial phase of the impact, and that only after substantial glove compression and consequent hardening would capacity for target deformation become the main determinant of the force curve. The magnitude of impact buffering provided 
by the target material would then depend not just on the properties of the material but also on the extent to which buffering had already occurred during glove deformation. Accordingly, in the case of the ARLI glove, the fact that the protective effect of increasing the thickness of the force plate covering was smaller than for the other glove types may have been largely due to prior occurrence of more substantial force damping through glove compression and air release.

Our examination of the force-time curves led us to simplistically conceptualise them as being describable in terms of four sequential but somewhat overlapping events-glove deformation, target deformation, target recovery and glove recovery-with the first two occurring during the lead-up to peak impact force and the latter two following it. Doubling the thickness of the mat covering the force plate appeared to have little effect on the timing of the glove deformation phase or the extent of impact damping resulting from it. It did, however, provide
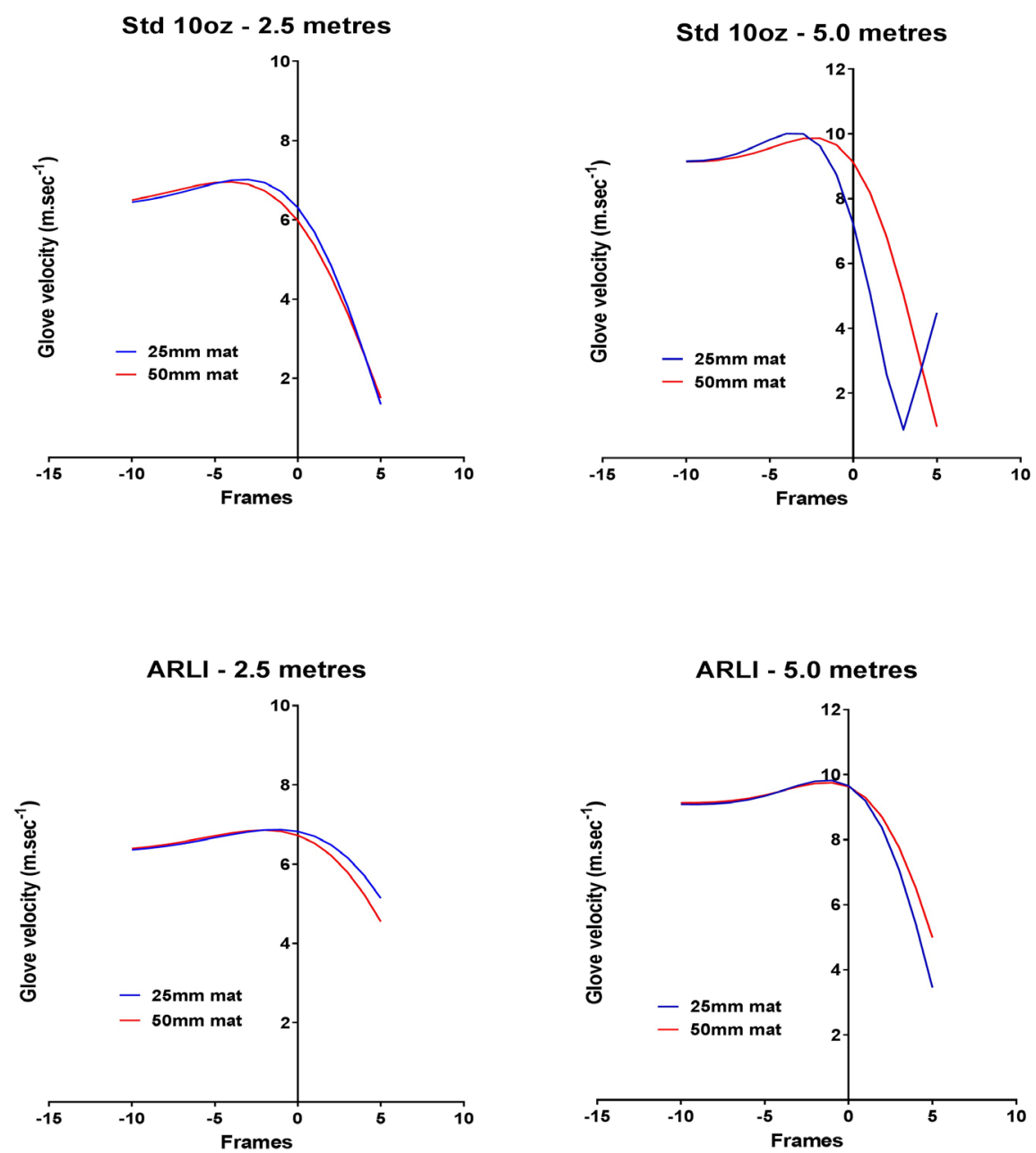

Figure 8. Pre-impact glove velocities measured using Vicon Motion Capture system. The velocities are shown from 10 video frames before to 5 frames after contact between glove and force plate and represent means of three glove drops. In the top right panel, the upward inflection of the blue line from 3 - 5 frames after glove contact with the force plate reflects velocities recorded as the glove rebounded away from the force plate. 
Std $100 z$

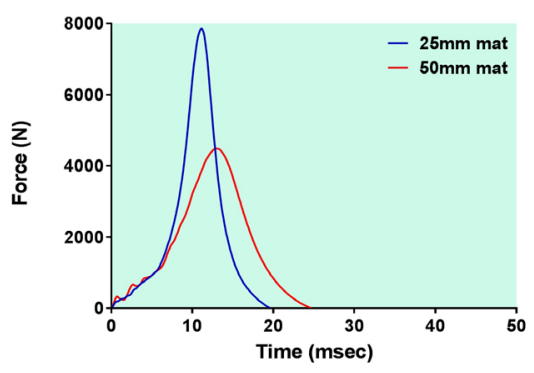

SBLI

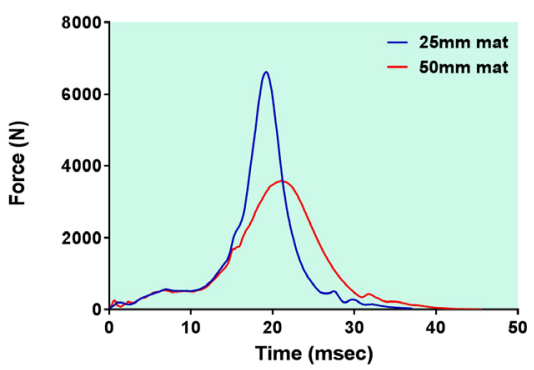

Std $160 z$

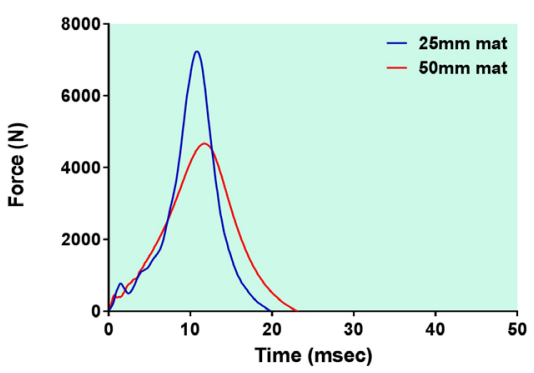

ARLI

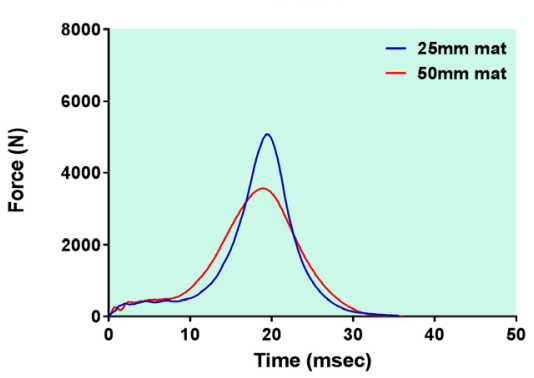

Figure 9. Force-time curves for different gloves dropped from a height 3.5 metres on to a force plate covered by EVA mats of two different thicknesses. The blue line relates to a mat thickness of $25 \mathrm{~mm}$ and the red line to a mat thickness of $50 \mathrm{~mm}$. The results shown are indicative of those obtained across the whole range of drop heights.

scope for greater target deformation and therefore a longer period of impact. For the Std $10 \mathrm{oz}$, Std $16 \mathrm{oz}$ and SBLI gloves contact time was increased at all drop heights, while for the ARLI glove there was little or no increase until the final drop height of 5.0 metres, and even then the change was relatively small (Figure 10). This suggests that the performance of the ARLI glove was less dependent on target characteristics. In general, greater increases in contact time were associated with proportionally greater protective effects of the additional force plate padding.

Computation of areas under the force-time curves yielded values very similar to those calculated in our previous study, where the thickness of the mat was only $25 \mathrm{~mm}$ (Figure 11). Over 24 combinations of glove type and drop height, there were 17 in which values for the $25 \mathrm{~mm}$ and $50 \mathrm{~mm}$ mat thicknesses were within $2 \%$ of each other, and another five where the difference was less than $2.5 \%$. Given that pre-impact glove velocities determined with the Vicon Motion Capture system were slightly lower with the thicker mat, we expected that the calculated area-under-the-curve might also be lower under this condition, but no such effect was detected.

As in our earlier research with a $25 \mathrm{~mm}$ thick mat, the area-under-the-curve values with the $50 \mathrm{~mm}$ mat were greatest for the Std $16 \mathrm{oz}$ glove and the values for the Std $10 \mathrm{oz}$ and ARLI gloves were very similar to each other. Again, the values for the SBLI glove were less than those for the Std 16 oz glove, but slightly higher than those for the other two glove types. Given that the SBLI glove had the lowest mass, the explanation for the latter finding is unclear, although the 

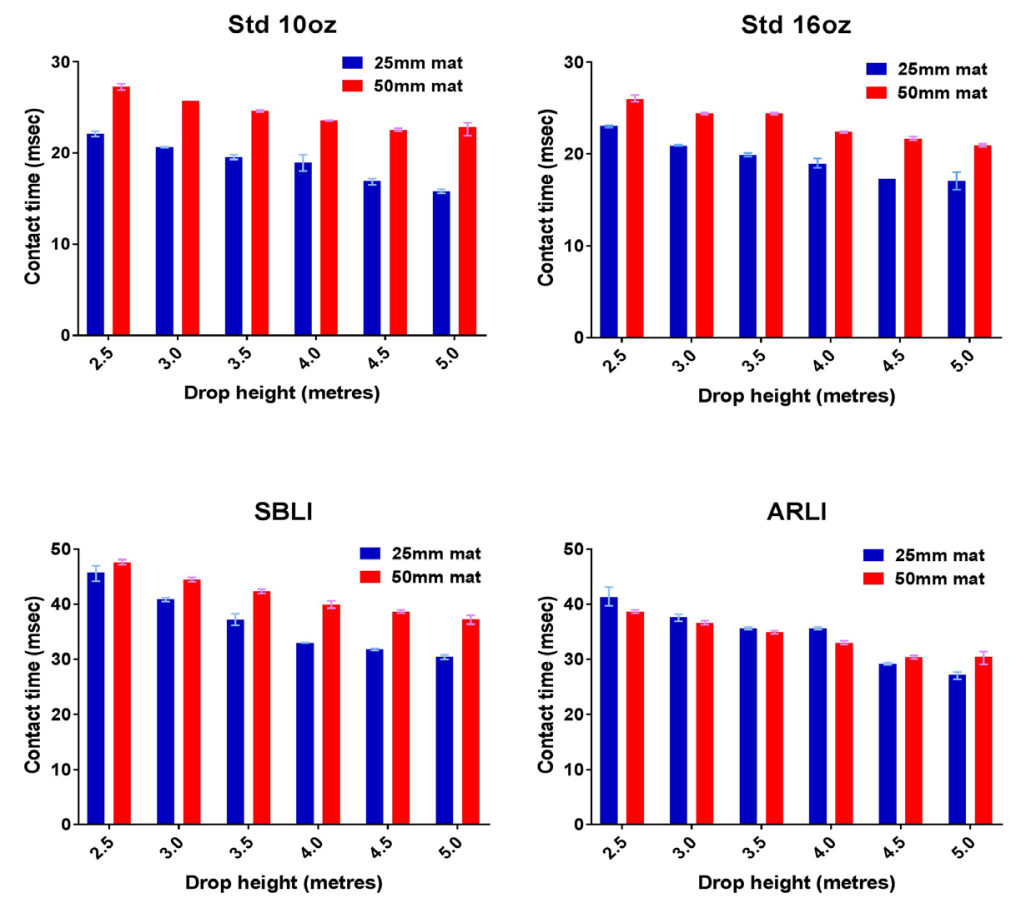

Figure 10. Effect of the thickness of force plate padding on force plate contact times with different combinations of glove type and drop height. Each bar represents a mean for three drops and the range of the readings is also shown.

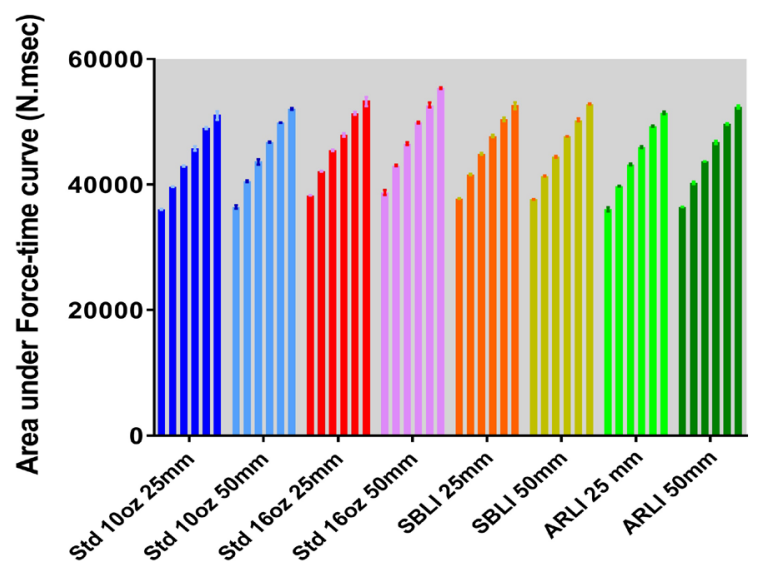

Figure 11. Effect of combination of glove type and mat thickness on area under the force-time curve for different drop heights. The bars show means and ranges for three glove drops. For each glove type, the progression of bars from left to right is associated with 0.5 increments in drop height, with the first bar relating to a drop height of 2.5 metres and the last to a drop height of 5.0 metres.

fact that this glove contained the smallest amount of foam may have caused it to have less capacity to internally store some of the impact energy.

In addition to the above variables, we determined rates of force development. This was accomplished by calculating changes in force over running periods of $0.5 \mathrm{msec}$ and multiplying the results by two to yield measurements in N. $\mathrm{msec}^{-1}$. Consequently, our first data point corresponded to $0.6 \mathrm{msec}$ after glove contact 
with the force plate and new data points when then generated for every further period of $0.1 \mathrm{msec}$ until glove contact ceased. Curves showing progression in rate of force of development when gloves were dropped on to the force plate covered with the $50 \mathrm{~mm}$ mat are presented in Figure 12.

For each glove, a distinctive "signature" curve was evident. In the case of the Std 16 oz glove, there was a sharp rise in rate of force development immediately upon impact with the force plate, followed by a period of marked oscillation. The curve for the Std $10 \mathrm{oz}$ glove also had these characteristics, but the spike associated with initial impact and the subsequent oscillations were generally smaller in magnitude. Peak rate of force development always occurred slightly later for the Std $10 \mathrm{oz}$ than for the Std 16 oz glove. The curve for the SBLI glove showed much less initial oscillation but its subsequent ascending phase always incorporated a sharp spike followed by oscillation. The ARLI glove produced a much smoother (less oscillating) curve, suggesting less force plate vibration. Compared to the Std $10 \mathrm{oz}$ and Std $16 \mathrm{oz}$ gloves, both pneumatic gloves delayed
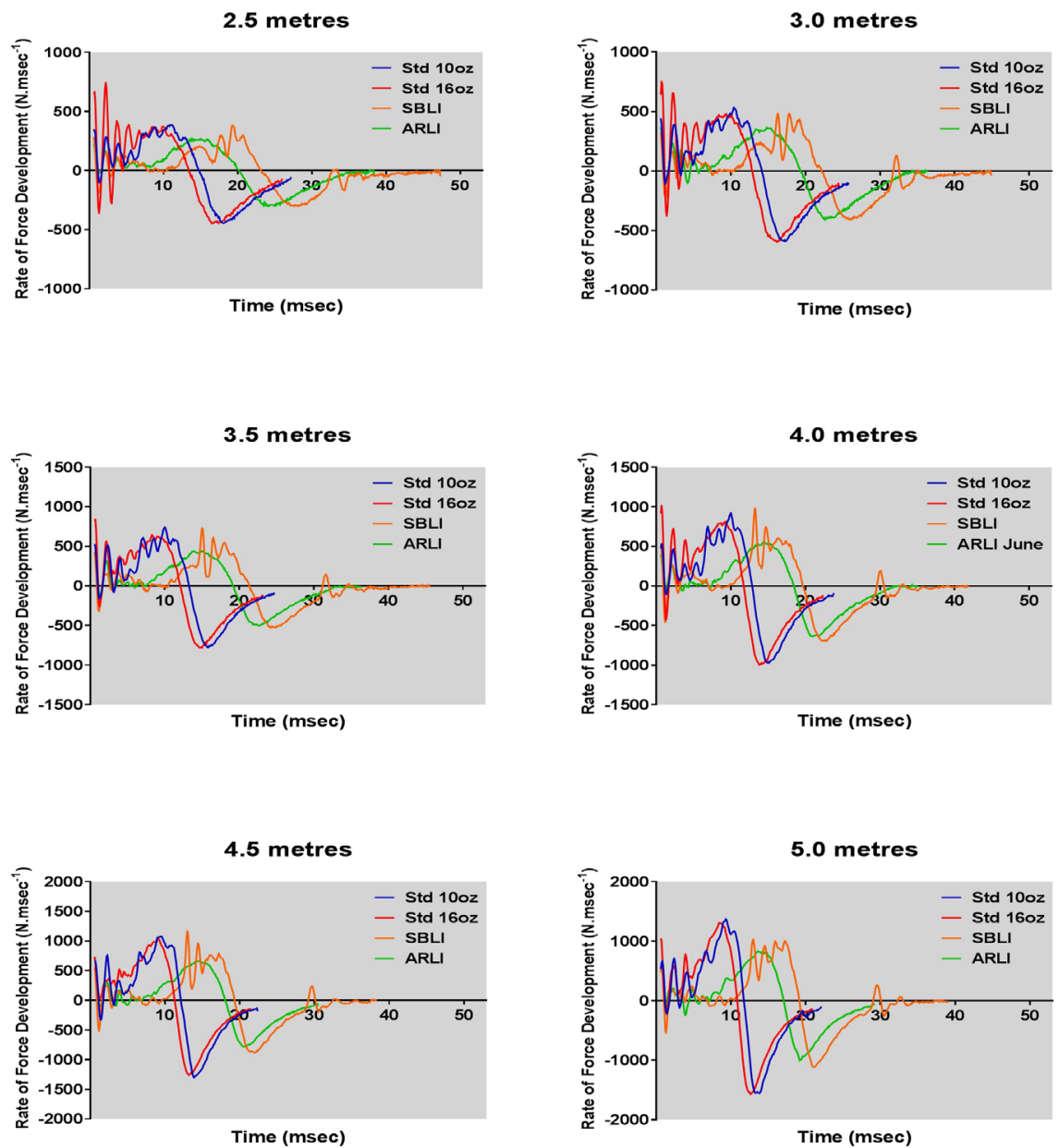

Figure 12. Curves showing rates of force development for four gloves dropped from various heights on to a force plate covered by a $50 \mathrm{~mm}$ thickness of EVA75 material. Each curve relates to the glove drop that produced the highest peak impact force reading from three drops performed under the specified condition. 
the occurrence of peak rate of force development. Importantly, the ARLI glove generated a lower peak than any other of the other gloves.

Curves incorporating essentially the same distinctive features were observed also in our experiment where the thickness of the mat covering the force plate was only $25 \mathrm{~mm}$, but in that experiment the rates of force development were considerably higher (Figure 13).

The influence of glove type and drop height on the peak rates of force development recorded with the $50 \mathrm{~mm}$ mat covering the force plate is presented in Figure 14. The ARLI glove produced both lower and more consistent values than any of the other gloves. The greater consistency was likely due to the smoother curves.

Figure 15 shows how mat thickness influenced the percentage by which the ARLI glove reduced the peak rate of force development relative to that seen with the Std $10 \mathrm{oz}$ glove. The effect of mat thickness lessened as the height from which gloves were dropped increased, and at a drop height of 5.0 metres the reduction in peak rate of force development provided by the ARLI glove was $~ 49 \%$ with both the $25 \mathrm{~mm}$ and $50 \mathrm{~mm}$ mats.

The progressive convergence occurred because the slope of the curve relating peak rate of force development to drop height decreased less for the Std $10 \mathrm{oz}$ glove than for the ARLI glove in response to doubling of mat thickness (Figure 16). This meant that increasing mat thickness resulted in gradual widening of the gap between values for the Std $10 \mathrm{oz}$ and ARLI gloves as drop height increased, with consequent rise of the relative protective effect offered by the ARLI glove.

The key point here, though, is that when a $50 \mathrm{~mm}$ thick mat was placed over the force plate with a view to making peak impact force readings for the Std 10 oz glove close to those reported by other researchers for punches delivered by boxers to the heads of Hybrid III crash test manikins [2] [3] or to opponents
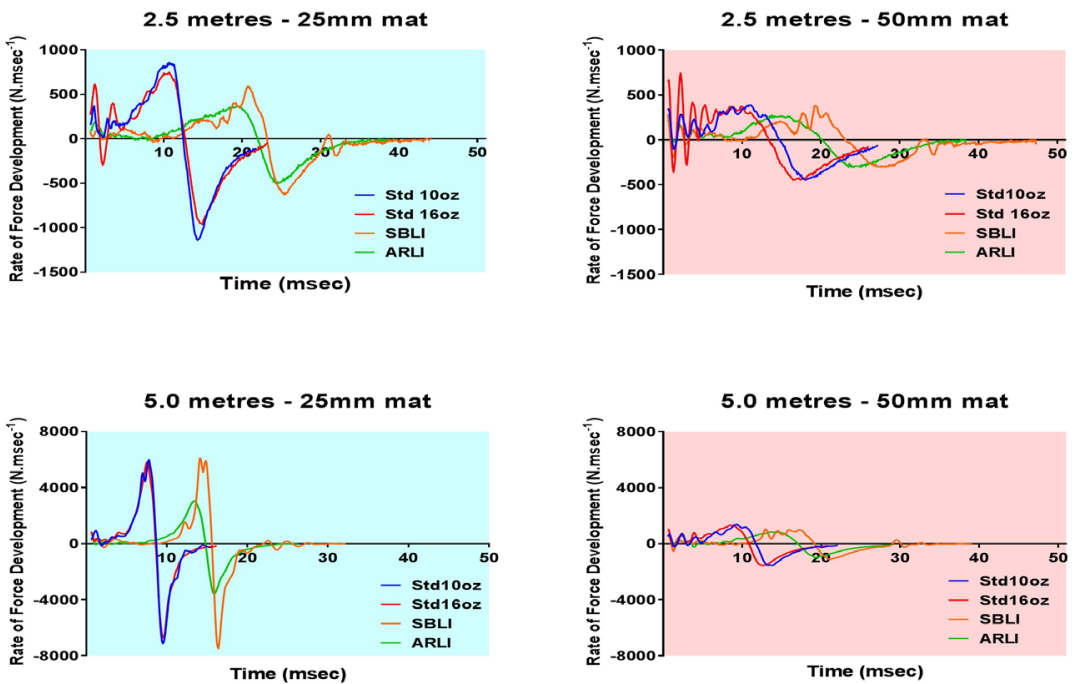

Figure 13. Effects of thickness of force plate covering on rates of force development recorded with dropping of different gloves from heights of 2.5 and 5.0 metres. Note that scaling on the $y$-axis of the graphs differs between the top and bottom rows. 


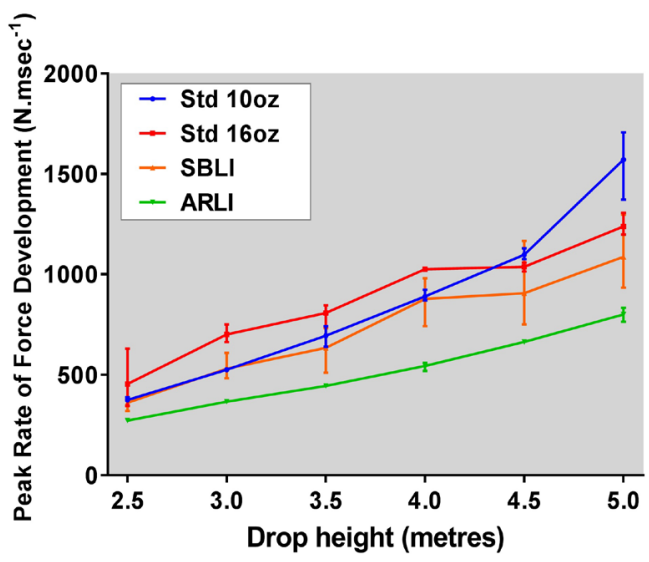

Figure 14. Effect of glove type and drop height on peak rate force development when gloves were dropped on to a force plate covered by a $50 \mathrm{~mm}$ thick mat of EVA75 material. Each point on the graph is a mean of three drops, and ranges for the three drops are also shown. There are some points at which bars indicating the range cannot be seen because the range was of very low magnitude.

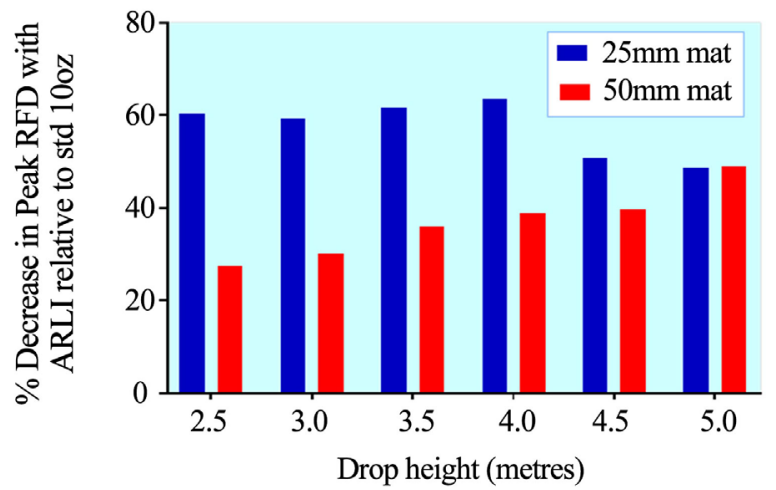

Figure 15. Effect of thickness of force plate covering on percentage decrease in peak rate of force development (Peak RFD) provided by ARLI glove relative to Std 10 oz glove at various drop heights. Each bar on the graph represents a mean of three glove drops.

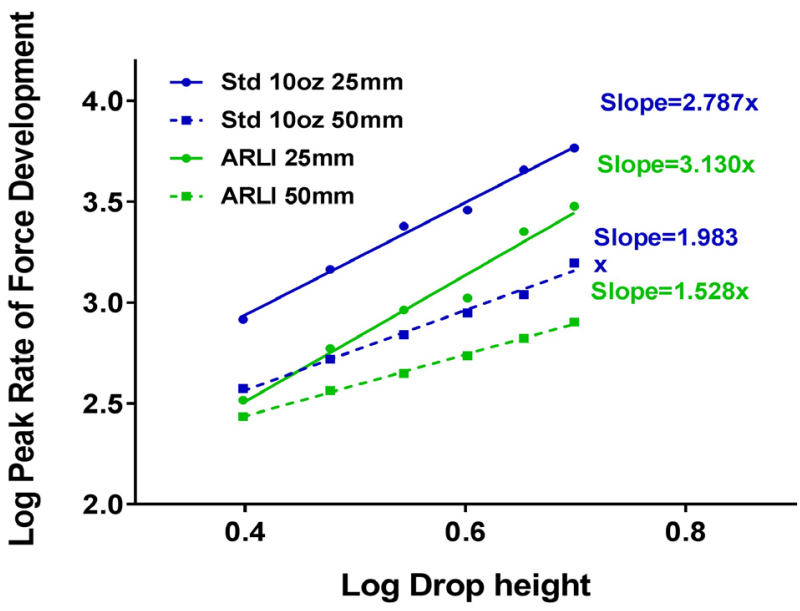

Figure 16. Changes in slope of relationship between drop height and peak rate of force development for two different gloves (Std $10 \mathrm{oz}$ and ARLI) as a function of thickness of force plate covering. 
during actual competition [4], the ARLI glove was able to reduce peak rate of force development by $27 \%$ - 49\% compared to that measured with the Std $10 \mathrm{oz}$ glove. Furthermore, the reduction became larger as drop height and therefore pre-impact glove velocity increased. The ARLI glove also produced peak rates of force development that were $25 \%$ - 37\% below those observed with the SBLI glove, despite these two gloves generating quite similar peak force readings across the range of drop heights.

\section{Discussion}

To facilitate assessment of real-world ability of pneumatic boxing gloves to mitigate risk of injury to an opponent, we sought to produce a target that could buffer impacts to an extent that is apparently characteristic of humans. To guide us in this task, we depended primarily on scientific literature describing peak impact forces measured when accomplished boxers delivered maximal punches to the heads of Hybrid III crash test manikins [2] [3], since considerable effort has been devoted to validating these manikins as human surrogates. We also took account of data from one study in which peak forces were measured during boxing matches [4]. Synthesis of the available literature suggested that the characteristics of our target should be such that the combination of a pre-impact impact glove velocity of $\sim 10.0 \mathrm{~m} \cdot \mathrm{sec}^{-1}$ and an effective impact mass of $\sim 3.0 \mathrm{~kg}$ would produce a peak force of $\sim 5500 \mathrm{~N}$ for a conventional $10 \mathrm{oz}$ glove. We found that covering an in-floor force plate with a $50 \mathrm{~mm}$ thick mat of EVA75 material came acceptably close to meeting this criterion. With the $50 \mathrm{~mm}$ covering in place, dropping of a Std $10 \mathrm{oz}$ glove containing a mechanical fist with a mass of just over $3.0 \mathrm{~kg}$ on to the force plate from a height of 5.0 metres produced a mean pre-impact glove velocity of $10.01 \mathrm{~m} \cdot \mathrm{sec}^{-1}$ and a mean peak impact force of $6514 \mathrm{~N}$-approximately half the level that we measured in earlier research with a $25 \mathrm{~mm}$ mat covering the force plate.

We set out to determine whether use of a target with greater inherent impact-damping capability would substantially or even completely negate the protective effect that our previous research [1] had shown could be provided by a pneumatic glove incorporating a mechanism for air release upon impact and subsequent air reuptake (i.e. the ARLI glove). The data revealed that the magnitude of the protective effect afforded by the ARLI relative to the Std 10 oz glove was reduced. Nevertheless, the ARLI glove still afforded clear protection across a whole range of drop heights that generated peak pre-impact glove velocities from just under $7.0 \mathrm{~m} \cdot \mathrm{sec}^{-1}$ to $\sim 10.0 \mathrm{~m} \cdot \mathrm{sec}^{-1}$. It decreased peak impact force by an overall average of $19.5 \%$, whereas this average was $33.0 \%$ when a $25 \mathrm{~mm}$ force plate covering was used. It also decreased peak rate of force production, a parameter known to be influential in many tissue injuries [8] [9] [10] and perhaps in the pathogenesis of concussion [11]. This decrease was considerable and became greater as drop height increased, reaching $49 \%$ at a drop height of 5.0 metres.

Another aim of the current experiment was to investigate the possibility that 
with a more damped target, a pneumatic glove with a sealed bladder (SBLI) could be just as comprehensively protective as one permitting exchange of air with the external environment (ARLI), since the impact-damping capability of the SBLI glove might no longer "bottom out" at higher impact velocities as had evidently occurred in our earlier trials with a $25 \mathrm{~mm}$ force plate covering. We found that with use of the $50 \mathrm{~mm}$ covering the bottoming out was indeed avoided. At all drop heights from 2.5 to 5.0 metres, the reduction in peak impact force provided by the SBLI glove relative to the Std $10 \mathrm{oz}$ glove became quite similar to that afforded by the ARLI glove. The ARLI glove remained superior, however, in terms of its ability to reduce peak rate of force development. This superiority was evident at every drop height. Overall, values for the ARLI glove were lower than those for the SBLI glove by an average of $29.7 \%$.

A question arises concerning the degree to which the impact-damping characteristics of the $50 \mathrm{~mm}$ EVA75 mat truly represented those of the human body. It is entirely conceivable that the efficacy of devices such as pneumatic gloves in complementing other impact-damping mechanisms might relate not just to the quantitative effects of those mechanisms but also to their nature. For example, a target that has low compressibility but considerable scope for movement could offer the same total impact damping capacity as one with the opposite characteristics but might interact differently with a given impacting object. Consequently, our findings will eventually need to be checked through studies involving targets with greater bio-fidelity.

Impact damping capacities and characteristics of the human body obviously differ between anatomical locations. Studies of peak impact forces generated when boxers strike Hybrid III crash test manikins [2] [3] have been confined to impacts to the head, which through its connection to the neck has some freedom of movement. Peak impact forces with impacts to the torso may be quantitively quite different, and this is pertinent since rib, lung, heart and abdominal organ injuries are known to occur in boxing [12] [13] [14] [15] [16]. Even for the head, impact damping characteristics appear to be site-dependent. It has been reported that when the head is unprotected, impact to the side of the head (the temporo-parietal region) poses the highest risk of concussive injury [17] [18] [19]. The temporo-parietal region deforms more in response to a given standardized impact [18], and while this may be due largely to the geometric shape of the human head, the fact that bone is thinner in this region of the skull than in the frontal and occipital regions could be a contributing factor. Ruan and Prasad [20] have reported an inverse relationship between skull bone thickness and deformability and have noted that protection of the skull and brain increases with increasing bone thickness.

Individual differences in anatomy may also influence impact damping qualities. There is large inter-individual variation in bone thickness. In post-mortem autopsies of 65 adult males, Mahinda and Murty [21] found that the range in bone thickness was $3.5-7.2 \mathrm{~mm}$ for the parietal bone, $2.6-8.0 \mathrm{~mm}$ for the tem- 
poral bone, $4.0-11.0 \mathrm{~mm}$ for the frontal bone and $6.0-10.1 \mathrm{~mm}$ for the occipital bone. The thickness of the sternum at the junction of the manubrium and the body ranged from $9.0-21.0 \mathrm{~mm}$. Comparable variations were observed amongst 10 adult females. Schlecht et al. [22] noted the existence of distinct skeletal phenotypes characterized by "slender" and "robust" bones. After adjusting for differences in body size, they observed a significant positive correlation between robustness (quantified as bone cross-sectional area relative to length) and bone strength. For men and women respectively, slender bones were $1.7-2.3$ and $1.3-$ 2.8 times less stiff and strong than robust bones.

There are also large individual differences in the thickness of muscle and subcutaneous fat. Rankin et al. [23] used real-time ultrasound imaging to measure the resting thicknesses of four abdominal muscles (internal oblique, external oblique, tranversus abdominis and rectus abdominis) in 68 adult females and 55 adult males. Total thickness of the abdominal muscular wall was also determined at precise anatomical locations in its upper and lower regions. For each of the muscles, between-subject variability in thickness was substantial as indicated by coefficients of variation ranging from $14.4 \%-30.5 \%$ for the females and $16.6 \%$ $28.9 \%$ for the males. Total abdominal muscular thickness in the lower right region of the wall averaged $2.96 \mathrm{~cm}$ for the females but the $95 \%$ confidence interval extended from 2.04 to $3.88 \mathrm{~cm}$. For the males, the mean thickness was 3.86 $\mathrm{cm}$ with the $95 \%$ confidence interval extending from 2.58 to $5.14 \mathrm{~cm}$ (values that coincidentally corresponded quite closely to the two different mat thicknesses employed in our experiment). Subcutaneous fat thicknesses are even more variable. Using an ultrasonic measurement technique, Leahy et al. [24] found that the abdominal subcutaneous fat thickness of 83 young adult men ranged from 1.0 to $57.3 \mathrm{~mm}$, while the range for 52 young adult women was $10.1-74.0 \mathrm{~mm}$. There is evidence that increased thickness of abdominal subcutaneous fat is protective against abdominal injuries resulting from motor vehicle accidents [25], highlighting the potential role of this layer in impact damping.

The implication of the above is that within human populations participating in boxing there is likely to be considerable diversity in the thickness, proportional composition and mechanical qualities of the interface between an impact site and internal anatomical structures. Studies based on average characteristics of the interface may have limited applicability to people at the extremes of the distribution. Comprehensive determination of the potential protective effects of pneumatic boxing gloves requires understanding of the effects of realistic interface variation. The experiment reported in this paper provides a step toward development of this understanding. It suggests that the effectiveness of the ARLI pneumatic glove is relatively greatest when biological impact damping is least. This can be regarded as a key feature of the glove.

An interesting and possibly very important finding of our study concerns the effects of the different gloves on rate of force development. The relatively smooth curve observed with the ARLI glove probably indicates that it caused the least force plate vibration. Although the mechanisms of cerebral concussion are 
complex [26] and not yet completely understood [27], it has long been suspected that vibration of the skull, and hence the brain, might play a role. Stoyanovski and Grozeva [28] report that the possibility was first raised in 1774. It was also mentioned by Franke [29] in the mid-1950s. One idea is that an impact producing a vibration frequency close to the natural resonant frequency of the brain elicits an increase in the amplitude of brain oscillation, producing strains that can damage neural tissue [30]. This is analogous to a situation in which structural failure of a building may occur due to an earthquake that leads the building to sway at its natural resonant frequency. It has also been proposed that with the cerebral cortex pushed hard up against the skull due to differences in the timing of impact-induced acceleration or deceleration of the two structures, vibration of the skull can produce cortical contusion [31].

Recently, Laksari et al. [32] used head impact kinetic data from 189 collisions occurring in sporting events as inputs to a finite element model. Two of the impacts had caused concussions, and one had been associated with loss of consciousness. The modelling revealed that in the latter case vibration frequencies in different regions of the brain became less uniform, leading to out-of-phase oscillations between regions. This produced high levels of strain, particularly in the corpus callosum and periventricular white matter, areas in which neuronal axons are known to be susceptible to injury produced by stretching. Axonal injury is thought to be integrally involved in the pathogenesis of concussion [33] [34]. Laksari et al. [32] considered that non-uniformities in vibration were likely due to a combination of impact magnitude, skull-brain geometry and variation in the material properties of the brain. It was concluded that the way in which the brain vibrates in response to impact may be a major determinant of the risk and severity of concussion. It is possible that vibration asymmetries contribute also to injury of other organs and structures. In any event, the apparent ability of our ARLI glove to greatly reduce target vibration may be another positive attribute. Martin [31] argues that the risk of acute brain trauma resulting from an impact is highly dependent on what happens in the first five msec after impact initiation, partly because this is when vibration characteristics are typically established. It is during this 5-msec period that rate of force development differs most between our ARLI pneumatic glove and conventional boxing gloves. The SBLI glove likewise differs from conventional gloves during this period but because of its particular mechanics some oscillation in rate of force development, probably indicating target vibration, occurs later.

An unexpected finding of our research was that whereas the peak impact force was slightly lower for the Std $16 \mathrm{oz}$ glove than the Std $10 \mathrm{oz}$ glove when the thickness of the mat covering the force plate was $25 \mathrm{~mm}$, the reverse was true when the $50 \mathrm{~mm}$ mat was used. It can be speculated that the thicker force plate padding diminished the effects of the additional padding incorporated into the Std $16 \mathrm{oz}$ glove and increased the relative effect of its extra mass. It is noteworthy, however, that testing of the Std $16 \mathrm{oz}$ glove with the $50 \mathrm{~mm}$ mat occurred at 
the very end of a long series of glove drops. A possibility that by then the impact damping capacity of the mat was becoming imperceptibly compromised cannot be excluded.

The merits or otherwise of boxing are subject to fervent debate [35]. Arguments against the sport are centred largely around the intent of contestants to harm each other and the attendant risks of serious acute and chronic injury, and even death [36]. Smillie [37] contends that while many sports are metaphors for battle, boxing is the real thing, and should have no place in the modern sporting landscape. Over recent years, though, modified forms of boxing aimed at addressing such objections have emerged in Australia [38] and elsewhere [39]. The first author of this paper ran a popular modified boxing program at a Police Community Youth Club in Canberra for five years. The high value that the participants placed on safety [40] stimulated a quest to develop gloves capable of markedly reducing impact forces. For us, that quest remains focused chiefly on augmenting modified boxing initiatives, where early adoption of the gloves is more likely. In most modified boxing situations, forceful punching is actively discouraged, although impacts of higher than desired velocity can sometimes accidentally occur. Suitability of pneumatic gloves to these situations therefore depends on their ability to diminish impact forces and rates of force development across a wide range of impact conditions. The results of the present study engender confidence that the ARLI glove satisfies this requirement.

\section{Conclusion}

Target characteristics influenced not just the peak impact forces produced by given levels of total impact energy generated by simulation of boxing punches, but also the relative protective effects of different glove types. Even with a doubling of target padding, however, a pneumatic glove incorporating a mechanism for air exchange with the external environment remained capable of reducing peak impact forces to levels well below those observed with conventional $10 \mathrm{oz}$ and $16 \mathrm{oz}$ gloves, and this was true across a wide range of pre-impact glove velocities. Its damping of peak impact forces was no longer greatly superior to that of a pneumatic glove incorporating a sealed bladder, but it still surpassed that glove and the conventional gloves in terms of ability to reduce peak rates of force development. Its sustained effectiveness under altered impact conditions suggests that it deserves to be the focus of continuing developmental efforts.

\section{Acknowledgements}

This research was supported by grants from the Australian Olympic Committee (through the Olympic Solidarity Program) and the Queensland Academy of Sport. The Canberra Police Community Youth Club provided substantial in-kind support. Acknowledgement is due also to Geordie Ferguson of Stellen Studio, Anthony Ashmore of AJA Engineering, and Luke and Katie Eldridge for 
design and manufacture of gloves and other equipment employed in the research. Jamie Plowman and Michael Steinebronn of the Australian Institute of Sport, Bill Shelley and Associate Professor Stephen Trathen of the University of Canberra, and Dr. Richard Helmer of Superinteractive Pty Ltd. all provided valuable advice, and Dr. Christopher Barnes of the University of Canberra assisted greatly with data collection.

\section{References}

[1] Perkins, P., Jamieson, A., Spratford, W. and Hahn, A. (2018) Evaluation of Ability of Two Different Pneumatic Boxing Gloves to Reduce Delivered İmpact Forces and İmprove Safety. World Journal of Engineering and Technology, 6, 457-491. https://doi.org/10.4236/wjet.2018.62028

[2] Waliliko, T.J., Viano, D.C. and Bir, C.A. (2005) Biomechanics of the Head for Olympic Boxer Punches to the Face. British Journal of Sports Medicine, 39, 710-719. https://doi.org/10.1136/bjsm.2004.014126

[3] Mack, J., Stojsih, S., Sherman, D., Dau, N. and Bir, C. (2010) Amateur Boxing Biomechanics and Punch Force. Proceedings of 28 th International Conference on Biomechanics in Sport, Michigan, 19-23 July 2010, 19-23.

[4] Pierce, J.D., Reinbold, K.A., Lyngard, B.C., Goldman, R.J. and Pastore, C.M. (2006) Direct Measurement of Punch Force during Six Professional Boxing Matches. Journal of Quantitative Analysis in Sports, 2, 1-17. https://doi.org/10.2202/1559-0410.1004

[5] Margetts, M.J. (1986) The Damaging Punch. British Medical Journal, 292, 489. https://doi.org/10.1136/bmj.292.6518.489-a

[6] International Boxing Association (2017) AIBA Technical Rules: Effective as of April 26, 2017. http://www.aiba.org/aiba-technical-competition-rules/

[7] Johnny, N. (2010) What Boxing Gloves to Use? ExpertBoxing.com. https://www.expertboxing.com/boxing-basics/boxing-equipment/what-boxing-glov es-to-use

[8] Cooper, G.J. and Taylor, D.E.M. (1989) Biophysics of İmpact İnjury to the Chest and Abdomen. Journal of the Royal Army Medical Corps, 135, 58-67. https://doi.org/10.1136/jramc-135-02-04

[9] Tran, N.T., Watson, N.A., Tencer, A.F., Ching, R.P. and Anderson, P.A. (1995) Mechanism of the Burst Fracture in the Thoracolumbar Spine: The Effect of Loading Rate. Spine, 20, 1984-1988. https://doi.org/10.1097/00007632-199509150-00004

[10] Ewers, B.J., Javaraman, V.M., Banglmaier, R.F. and Haut, R.C. (2000) The Effect of Loading Rate on the Degree of Acute İnjury and Chronic Conditions in the Knee after Blunt İmpact. Stapp Car Crash Journal, 44, 299-313.

[11] Zhang, L., Yang, K.H., King, A. and Viano, D.C. (2003) A New Biomechanical Predictor for Mild Traumatic Brain İnjury-A Preliminary Finding. Summer Bioengineering Conference, Key Biscayne, 137-138.

[12] Oelman, B.J., Rose, C.M.E. and Arlow, K.J. (1983) Boxing Injuries in the Army. Journal of the Royal Army Medical Corps, 129, 32-37.

https://doi.org/10.1136/jramc-129-01-10

[13] Belham, G.J. and Adler, M. (1985) Case Report: Pneumothorax in a Boxer. British Journal of Sports Medicine, 19, 45. https://doi.org/10.1136/bjsm.19.1.45 
[14] Bellotti, P., Chiarella, F., Domenicucci, S., Lupi, G. and Vecchio, C. (1992) Myocardial Contusion after a Professional Boxing Match. American Journal of Cardiology, 69, 709-710. https://doi.org/10.1016/0002-9149(92)90175-X

[15] Timm, K.E., Wallach, J.M., Stone, J.A. and Ryan, E.J. (1993) Fifteen Years of Amateur Boxing İnuries/İllnesses at the United States Olympic Training Center. Journal of Athletic Training, 28, 330-334.

[16] Potter, M.R., Snyder, A.J. and Smith, G.A. (2011) Boxing İnjuries Presenting to U.S. Emergency Departments, 1990-2008. American Journal of Preventive Medicine, 40, 462-467. https://doi.org/10.1016/j.amepre.2010.12.018

[17] Hodgson, V., Thomas, L. and Khalil, T. (1983) The Role of İmpact Location in Reversible Cerebral Concussion. Society of Automotive Engineers, Report No. 831618. https://doi.org/10.4271/831618

[18] Zhang, L., Yang, K.H. and King, A.I. (2001) Comparison of Brain Responses between Frontal and Lateral İmpacts by Finite Element Modeling. Journal of Neurotrauma, 18, 21-30. https://doi.org/10.1089/089771501750055749

[19] McIntosh, A.S., Patton, D.A., Frechede, B., Pierre, P.-A., Ferry, E. and Barthels, T. (2014) The Biomechanics of Concussion in Unhelmeted Football Players in Australia. BMJ Open, 4, e005078. https://doi.org/10.1136/bmjopen-2014-005078

[20] Ruan, J. and Prasad, P. (2001) The Effects of Skull Thickness Variation on Human Head Dynamic İmpact Responses. Stapp Car Crash Journal, 45, 85-102.

[21] Mahinda, H.A.M. and Murty, O.P. (2009) Variability in Thickness of Human Skull Bones and Sternum-An Autopsy Experience. Indian Journal of Forensic Medicine \& Toxicology, 126, 26-31.

[22] Schlecht, S.H., Bigelow, E.M.R. and Jepsen, K. (2014) Mapping the Natural Variation in Whole Bone Stiffness and Strength across Skeletal Sites. Bone, 67, 15-22. https://doi.org/10.1016/j.bone.2014.06.031

[23] Rankin, G., Stokes, M. and Newham, D.J. (2006) Abdominal Muscle Size and Symmetry in Normal Subjects. Muscle \& Nerve, 34, 320-326. https://doi.org/10.1002/mus.20589

[24] Leahy, S., Toomey, C., McCreesh, K., O’Neill, C. and Jakeman, P. (2012) Ultrasound Measurement of Subcutaneous Adipose Tissue Thickness Accurately Predicts Total and Segmental Body Fat of Young Adults. Ultrasound in Medicine \& Biology, 38, 28-34. https://doi.org/10.1016/j.ultrasmedbio.2011.10.011

[25] Wang, S.C., Bednarski, B., Patel, S., Yan, A., Kohoyda-Inglis, C., Kennedy, T., et al. (2003) Increased Depth of Subcutaneous Fat İs Protective against Abdominal İnjuries in Motor Vehicle Collisions. Annual Proceedings/ Association for the Advancement of Automotive Medicine, 47, 545-549.

[26] Hoshizaki, B., Post, A., Kendall, M., Karton, C. and Brien, S. (2013) The Relationship between Head İmpact Characteristics and Brain Trauma. Journal of Neurology \& Neurophysiology, 5, 181. https://doi.org/10.4172/2155-9562.1000181

[27] Meaney, D.F. and Smith, D.H. (2011) Biomechanics of Concussion. Clinics in Sports Medicine, 30, 19-30. https://doi.org/10.1016/j.csm.2010.08.009

[28] Stoyanovski, M. and Grozeva, M. (2005) Current Concepts on Morphogenesis of Cerebrocranial İnjuries. Trakia Journal of Sciences, 3, 1-5.

[29] Franke, E.K. (1954) The Response of the the Human Skull to Mechanical Vibrations. Wright Air Development Centre, Ohio, Report No. 54-24. https://doi.org/10.21236/AD0061817

[30] Willinger, R., Taleb, L. and Kopp, C.M. (1995) Modal and Temporal Analysis of 
Head Mathematical Models. Journal of Neurotrauma, 12, 743-754. https://doi.org/10.1089/neu.1995.12.743

[31] Martin, G. (2016) Acute Brain Trauma. Annals of the Royal College of Surgeons of England, 98, 6-10. https://doi.org/10.1308/rcsann.2016.0003

[32] Laksari, K., Kurt, M., Babaee, H., Kleiven, S. and Camarillo, D. (2018) Mechanistic İnsights into Human Brain İmpact Dynamics through Modal Analysis. Physical Review Letters, 120, Article ID: 138101. https://doi.org/10.1103/PhysRevLett.120.138101

[33] Bazarian, J.J., Zhong, J., Blyth, B., Zhu, T., Kavcic, V. and Peterson, D. (2007) Diffusion Tensor İmaging Detects Clinically İmportant Axonal Damage after Mild Traumatic Brain İnjury: A Pilot Study. Journal of Neurotrauma, 24, 1447-1459. https://doi.org/10.1089/neu.2007.0241

[34] Browne, K.D., Chen, X.-H., Meaney, D.F. and Smith, D.H. (2011) Mild Traumatic Brain İnjury and Diffuse Axonal İnjury in Swine. Journal of Neurotrauma, 28, 1747-1755. https://doi.org/10.1089/neu.2011.1913

[35] Perkins, P., Hahn, A., Lucas, R. and Keegan, R. (2014) The Boxing Conundrum: İs There a Place for a New Variant of the Sport? Journal of Research in Humanities and Social Science, 2, 9-25.

[36] Svinth, J. (2007) Death under the Spotlight: Analysing the Data. Journal of Combative Sport, 1-19.

[37] Smillie, M. (2003) There İs No Sport like Boxing. British Columbia Medical Journal, $45,473-474$.

[38] Hahn, A.G., Helmer, R.J., Mackintosh, C., Staynes, L.M. and Blanchonette, I. (2011) Technological Foundations and Current Status of a Modified, Low-Risk Form of Competitive Boxing (Box’Tag ${ }^{\bowtie}$ ). Sports Technology, 4, 178-184. https://doi.org/10.1080/19346182.2012.725413

[39] Light-Contact Boxing. http://www.light-contact.ch/4-1-Light-Contact-Boxing.html

[40] Perkins, P., Hahn, A., Keegan, R. and Collis, I. (2014) Why Do Community-Based Athletes Choose to Participate in a Modified, Low-Risk Form of Boxing? An Interpretative Phenomenological Analysis. Journal of Research in Humanities and Social Science, 2, 60-69. https://doi.org/10.9790/9467-2116069 